- Retrospective data on the outcome of non-restoration of carious deciduous teeth.

- The development of pain is related to age at diagnosis, cavity type and tooth type.

- The majority of carious deciduous teeth remained pain-free until exfoliated.

- The study may provide an aid to treatment planning.

\title{
The fate of 1,587 unrestored carious deciduous teeth: a retrospective general dental practice based study from northern England
}

\author{
R. S. Levine, ${ }^{1}$ N. B. Pitts ${ }^{2}$ and Z. J. Nugent ${ }^{3}$
}

\begin{abstract}
Objective To investigate the outcome of non-restoration of carious deciduous teeth by means of a retrospective analysis of clinical case notes of children regularly attending two general dental practices and receiving preventive care.

Design Using a carefully defined protocol the fate of deciduous teeth diagnosed as carious into dentine but symptomless and left unrestored was determined from the sequential examination of the clinical records of 481 children attending at least annually.

Results The age at initial diagnosis of carious teeth ranged from 1-12 years with the majority of cavities $(1,005)$ presenting by 6 years of age. In all, 1,587 teeth were followed until loss from the mouth. Of these, 190 $(12 \%)$ were extracted because of pain and a further $60(4 \%)$ became painful and were treated, leaving 1,337 (84\%) that remained symptomless until being lost. Of the 1,337 symptomless teeth, 178 were extracted under general anaesthesia at the same time as painful ones. The final group of 1,159 (74\%) teeth were exfoliated without causing pain after a mean survival time of 1,332 days. Excluding from the analysis the 178 extracted, but symptomless teeth, leaves a total of 1,409 teeth of which $18 \%$ gave pain and were extracted or treated and the remaining $82 \%$ exfoliated. The strongest determinant of pain was age on diagnosis, the other factors being tooth type and extent of the cavity when first seen. The carious teeth most likely to cause symptoms were found to be molars that developed cavities with pulpal involvement by the age of 3 years, $34 \%$ of which caused pain. In contrast, those least likely to cause pain were carious molar teeth presenting without pulpal involvement after 8 years, only $6 \%$ of which produced symptoms. Conclusion In these patients, the majority of unrestored carious deciduous teeth remain symptomless until shed. The results provide evidence to aid the treatment planning of carious deciduous teeth in children regularly receiving regular preventive dental care.
\end{abstract}

Caries of the deciduous dentition is a clinical problem that has abated within the higher socio-economic groups in many devel-

${ }^{1 *}$ GDP/Independent Scientific Adviser, 370 Alwoodley Lane, Leeds LS17 7DN; ${ }^{2}$ Unit Director, ${ }^{3}$ Statistician, Dental Health Services Research Unit, University of Dundee Dental School, Park Place, Dundee DD1 4HR

*Correspondence to: DrR. S. Levine

E-mail:ronnielevine@onetel.net.uk

\section{Refereed paper}

Received 23.07.01; Accepted 10.04.02

๑ British Dental Journal 2002; 193: 99-103 oped countries, including the UK in recent years. However, the most recent UK national survey of 5-years-olds found a dmf of 1.57 for the UK as a whole and levels of over 3 in many areas, especially in northern areas and areas of social deprivation. ${ }^{1}$ When caries occurs in deciduous teeth it can be one of the most difficult of clinical problems. Often, the child presents in pain with little if any experience of dental care and sometimes in a distressed state. In such cases treatment is essential and can be distressing to all involved. However, when the child is symptomless a clinical management decision has to be taken; to restore the carious teeth or not to do so. While this issue attracts increasing informal debate, there is little substantive evidence in the literature on which to base informed consideration.

The restoration of carious deciduous teeth is used as an indicator of the level of dental care (care index). Concern has been rightly expressed that the high level of untreated caries in some sectors of the UK child population may indicate a failure in primary dental care provision. The traditional approach to the management of carious deciduous teeth has been conventional restoration of all cavities and this approach is still strongly supported by one school of thought. ${ }^{2}$ While physical restoration of all cavities in deciduous teeth has the advantage of rendering the child dentally fit in the conventional sense, one possible consequence of such treatment at an early age is to produce a dental aversion, which may prevent the individual seeking regular dental care in latter years. In addition, little is known of the long-term benefits of restorative intervention in terms of improved function and freedom from pain and infection.

Carious lesions do not inevitably progress and while there is considerable anecdotal evidence from experienced dentists that unrestored carious deciduous teeth will often exfoliate without producing symptoms, there is little evidence in the literature on the fate of such teeth. The concept of a less operative approach to the management of carious lesions has been put forward in the past as a minority opinion. ${ }^{3}$ However, recent debate has emphasised the view that treatment for children must be appropriate to their feelings and fears with the aim of building a healthier dental future through confidence in dental care, while at the same time managing the carious process both effectively and appropriately. ${ }^{4}$

In the climate of evidence-based dentistry, to help put treatment planning on a sound basis, information is needed on the consequence(s) of leaving carious deciduous teeth unrestored. The aim 
of this study is to provide substantive evidence from a retrospective analysis of longitudinal clinical data on the fate of unrestored carious deciduous teeth.

\section{METHOD}

The setting for this longitudinal study was two general dental practices in West Yorkshire, England, one in Leeds and the other in Halifax, both being non-fluoridated areas. Both practices are located in health authority health centres together with other primary care services. The Leeds practice serves a multi-ethnic, inner city community with high levels of social deprivation and oral disease. The Halifax practice serves a largely white Caucasian community with a rather more mixed socio-economic profile. The 1999/2000 BASCD co-ordinated Dental Epidemiology Programme NHS survey of child dental health produced a mean dmft for 5-year olds of 2.03 for Leeds and 2.30 for Halifax (Calderdale and Kirklees) against a mean for the UK as a whole of $1.57 .{ }^{1}$ When the first of these practices was established in 1976, the prevalence of caries was much higher than today and the pressure on the available resources within the newly established practices required priority to be given to pain relief and treatment of carious permanent teeth. Asymptomatic carious deciduous teeth were frequently seen, but usually left unrestored and this policy continues. Management consists of the regular reinforcement of simple dietary and toothbrushing advice following the guidelines of the Health Education Authority. ${ }^{5}$ The detailed clinical records from these practices, extending for over 20 years, provide the source of the longitudinal data used in this study.

The protocol for routine clinical recording of deciduous caries was the same at both practices and remained unchanged from the establishment of the practices in 1976 (Halifax) and 1982 (Leeds) by the same dentist (RSL) and all clinical routines and administration were standardized between the practices. Lesions considered to be confined to enamel, such as uncavitated white spot lesions and fissure decalicification, (D1) were not recorded. Cavities extending into dentine were recorded by the normal convention indicating the surfaces involved. Teeth regarded as being cariously exposed were clearly charted as such. Radiographic assessment was not routinely used to determine the extent of cavities in deciduous teeth and charting was based solely on visual examination. The complaint of pain from a patient was always recorded as such, together with a note of the indicated teeth and any evidence of acute infection, as was the presence of symptomless chronic infection.

Two dental nurses, who had worked at each respective practice for over 15 years, extracted data from the clinical records. Working from a clearly defined protocol (Fig. 1) they examined the clinical records cards held at the practices in alphabetical order. In order to help ensure consistency of record keeping, only the records of patients under the care of one dentist (RSL) were examined. Record cards for children who were first seen by 12 years of age and subsequently attended at least annually for routine examination were selected and the clinical notes were sequentially reviewed to identify deciduous teeth recorded as carious but not initially restored. The initial diagnosis was recorded and classified as: code 1 - one surface cavity; code 2 - two or more surface cavities; code 3 - carious pulpal exposure. The initial diagnosis date was recorded and the history of each untreated carious

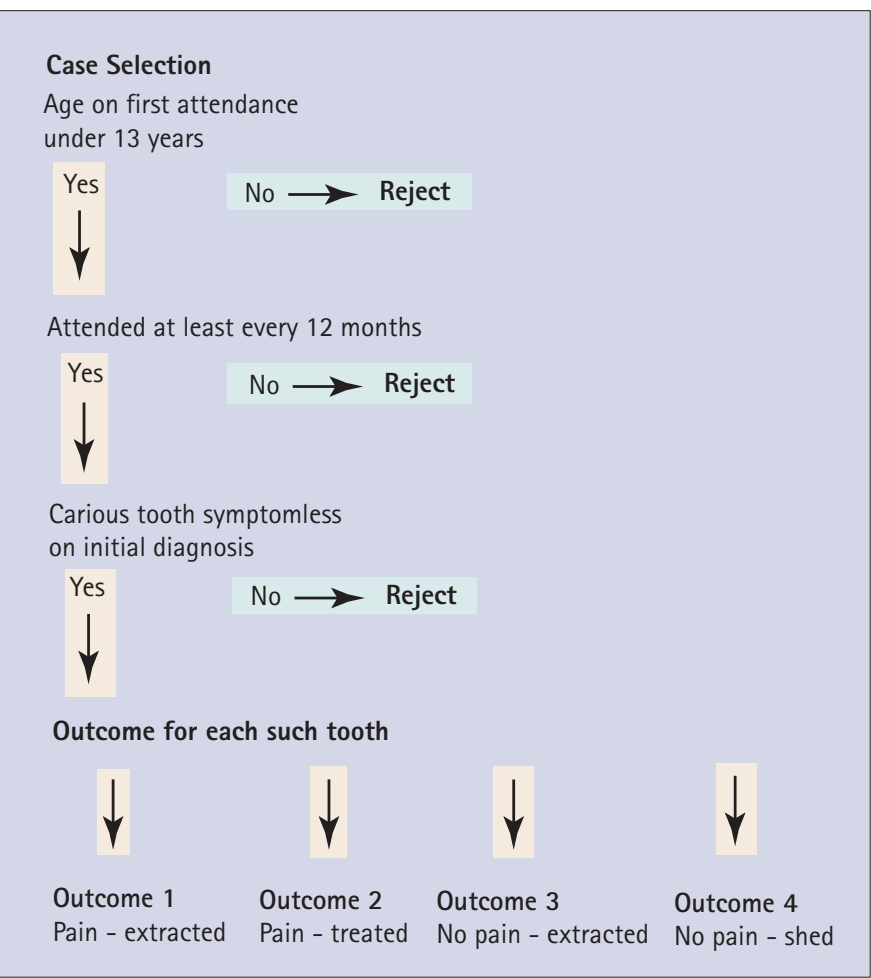

Fig. 1 Patient record search protocol - all record cards at practice are examined in alphabetical order)

tooth was then followed through the clinical notes to determine the outcome, which was placed in one of four outcome categories. These were:

Outcome 1 - extracted because of pain.

Outcome 2 - treated because of pain, including temporary or permanent restorations or the prescription of antibiotics.

Outcome 3 - remained symptomless but extracted together with other painful teeth under general anaesthesia.

Outcome 4 - remaining symptomless until exfoliation.

Finally, the outcome date was recorded. For the purposes of the study 'pain' included the presence of symptomless chronic infection. However, pain not resulting from caries, such as mucosa lesions, pericoronitis or discomfort from exfoliating teeth were excluded. Teeth were also excluded if there was any doubt about: the source of the pain, outcome, if restorative treatment appeared to have been provided for symptomless teeth, or if there was a break in the continuity of the record of more than one year. The data set also included date of birth for each subject and the notation of each carious tooth. Following initial instruction and a pilot study neither dental nurse had difficulty in using the search protocol and a re-examination of 25 cases from each practice revealed only one recording error.

\section{RESULTS}

In all, the fate of 1,587 carious deciduous teeth from 481 children were followed until loss from the mouth. The age range of the children at initial diagnosis of a lesion is given in Table 1, the majority

\begin{tabular}{|c|c|c|c|c|c|c|c|c|c|}
\hline AGE (YEARS) & $<3$ & 3 & 4 & 5 & 6 & 7 & 8 & 9 & $>9$ \\
\hline $\begin{array}{l}\text { Number of cavities } \\
n=1587(\%)\end{array}$ & $\begin{array}{r}127 \\
(8.0)\end{array}$ & $\begin{array}{r}212 \\
(13.4)\end{array}$ & $\begin{array}{r}264 \\
(16.6)\end{array}$ & $\begin{array}{r}201 \\
(12.7)\end{array}$ & $\begin{array}{r}201 \\
(12.7)\end{array}$ & $\begin{array}{r}208 \\
(13.1)\end{array}$ & $\begin{array}{r}122 \\
(7.7)\end{array}$ & $\begin{array}{r}156 \\
(9.8)\end{array}$ & $\begin{array}{r}96 \\
(6.0)\end{array}$ \\
\hline $\begin{array}{l}\text { Number of children } \\
n=481(\%)\end{array}$ & $\begin{array}{r}46 \\
(9.5)\end{array}$ & $\begin{array}{r}61 \\
(12.7)\end{array}$ & $\begin{array}{r}76 \\
(15.8)\end{array}$ & $\begin{array}{r}61 \\
(12.7)\end{array}$ & $\begin{array}{r}60 \\
(12.5)\end{array}$ & $\begin{array}{r}54 \\
(11.2)\end{array}$ & $\begin{array}{r}45 \\
(9.4)\end{array}$ & $\begin{array}{r}37 \\
(7.7)\end{array}$ & $\begin{array}{r}41 \\
(8.5)\end{array}$ \\
\hline
\end{tabular}


RESEARCH

\begin{tabular}{|c|c|c|c|c|c|c|c|c|c|}
\hline \multirow{3}{*}{ CAVITY TYPE } & \multirow[b]{3}{*}{ INCISORS } & \multicolumn{7}{|c|}{ NUMBERS OF AFFECTED TEETH (\% WITHIN EACH CAVITY TYPE GROUP) } & \multirow{3}{*}{$\begin{array}{c}\text { TOTAL } \\
\text { (\% OF TOTAL) }\end{array}$} \\
\hline & & \multicolumn{3}{|c|}{ UPPER TEETH } & \multicolumn{2}{|c|}{ LOWER TEETH } & \multirow[b]{2}{*}{ 1ST MOLAR } & \multirow[b]{2}{*}{ 2ND MOLAR } & \\
\hline & & CANINE & 1ST MOLARS & 2ND MOLAR & INCISORS & CANINE & & & \\
\hline $\begin{array}{l}\text { Single } \\
\text { surface }\end{array}$ & $\begin{array}{r}253 \\
(26.3) \\
\end{array}$ & $\begin{array}{r}35 \\
(3.6) \\
\end{array}$ & $\begin{array}{r}113 \\
(11.7) \\
\end{array}$ & $\begin{array}{r}180 \\
(18.7) \\
\end{array}$ & $\begin{array}{r}24 \\
(2.5) \\
\end{array}$ & $\begin{array}{r}16 \\
(1.7) \\
\end{array}$ & $\begin{array}{r}127 \\
(13.2) \\
\end{array}$ & $\begin{array}{r}215 \\
(22.3) \\
\end{array}$ & $\begin{array}{r}963 \\
(60.7 \%) \\
\end{array}$ \\
\hline $\begin{array}{l}\text { Multiple } \\
\text { surfaces }\end{array}$ & $\begin{array}{r}7 \\
(2.8) \\
\end{array}$ & $\begin{array}{r}1 \\
(0.4)\end{array}$ & $\begin{array}{r}132 \\
(52.2) \\
\end{array}$ & $\begin{array}{r}49 \\
(19.4) \\
\end{array}$ & $\begin{array}{r}2 \\
(0.8) \\
\end{array}$ & $\begin{array}{r}1 \\
(0.4)\end{array}$ & $\begin{array}{r}79 \\
(43.5) \\
\end{array}$ & $\begin{array}{r}31 \\
(12.3) \\
\end{array}$ & $\begin{array}{r}253 \\
(15.9 \%) \\
\end{array}$ \\
\hline $\begin{array}{l}\text { Pulpal } \\
\text { exposure }\end{array}$ & $\begin{array}{r}36 \\
(9.7)\end{array}$ & $\begin{array}{r}11 \\
(3.0)\end{array}$ & $\begin{array}{r}66 \\
(36.1)\end{array}$ & $\begin{array}{r}68 \\
(18.3\end{array}$ & $\begin{array}{r}3 \\
(0.8)\end{array}$ & $\begin{array}{r}6 \\
(1.6)\end{array}$ & $\begin{array}{r}84 \\
(48.8)\end{array}$ & $\begin{array}{r}97 \\
(26.1)\end{array}$ & $\begin{array}{r}371 \\
(23.4 \%)\end{array}$ \\
\hline
\end{tabular}

\begin{tabular}{|c|c|c|c|c|c|c|c|c|c|c|c|}
\hline \multirow[b]{2}{*}{ AGE (YEARS) } & \multirow[b]{2}{*}{$<3$} & \multirow[b]{2}{*}{3} & \multicolumn{7}{|c|}{ NUMBERS OF AFFECTED TEETH (\% WITHIN EACH AGE GROUP) } & \multirow[b]{2}{*}{$\begin{array}{c}\text { TOTAL } \\
\text { (\% OF TOTAL) }\end{array}$} & \multirow[b]{2}{*}{$\begin{array}{l}\text { SURVIVAL DAYS } \\
\text { MEAN (MEDIAN) }\end{array}$} \\
\hline & & & 4 & 5 & 6 & 7 & 8 & 9 & $>9$ & & \\
\hline $\begin{array}{l}\text { Outcome } \\
1 \text { Pain } \\
\text { Et extracted }\end{array}$ & $\begin{array}{r}32 \\
(25.2)\end{array}$ & $\begin{array}{r}39 \\
(18.4)\end{array}$ & $\begin{array}{r}40 \\
(15.1)\end{array}$ & $\begin{array}{r}23 \\
(11.4)\end{array}$ & $\begin{array}{r}15 \\
(7.9)\end{array}$ & $\begin{array}{r}19 \\
(9.6)\end{array}$ & $\begin{array}{r}13 \\
(10.6)\end{array}$ & $\begin{array}{r}5 \\
(3.2)\end{array}$ & $\begin{array}{r}4 \\
(4.2)\end{array}$ & $\begin{array}{r}190 \\
(12.0)\end{array}$ & 766 (490) \\
\hline $\begin{array}{l}2 \text { Pain } \\
\text { \&t treated }\end{array}$ & $\begin{array}{r}3 \\
(2.0)\end{array}$ & $\begin{array}{r}11 \\
(5.2)\end{array}$ & $\begin{array}{r}10 \\
(3.8)\end{array}$ & $\begin{array}{r}14 \\
(7.0)\end{array}$ & $\begin{array}{r}11 \\
(5.8)\end{array}$ & $\begin{array}{r}6 \\
(2.9)\end{array}$ & $\begin{array}{r}3 \\
(2.5)\end{array}$ & $\begin{array}{r}2 \\
(1.3)\end{array}$ & $\begin{array}{r}1 \\
(1.0)\end{array}$ & $\begin{array}{r}60 \\
(3.8)\end{array}$ & $649(480)$ \\
\hline $\begin{array}{l}3 \text { No pain } \\
\text { Et extracted }\end{array}$ & $\begin{array}{r}32 \\
(25.6)\end{array}$ & $\begin{array}{r}48 \\
(22.6)\end{array}$ & $\begin{array}{r}29 \\
(11.0)\end{array}$ & $\begin{array}{r}24 \\
(11.9)\end{array}$ & $\begin{array}{r}21 \\
(11.2)\end{array}$ & $\begin{array}{r}17 \\
(8.6)\end{array}$ & $\begin{array}{r}4 \\
(3.3)\end{array}$ & $\begin{array}{r}2 \\
(1.3)\end{array}$ & $\begin{array}{r}0 \\
(0)\end{array}$ & $\begin{array}{r}178 \\
(11.2)\end{array}$ & $650(471)$ \\
\hline 4 Exfoliated & $\begin{array}{r}60 \\
(47.2)\end{array}$ & $\begin{array}{r}114 \\
(53.8)\end{array}$ & $\begin{array}{r}185 \\
(70.1)\end{array}$ & $\begin{array}{r}140 \\
(69.7)\end{array}$ & $\begin{array}{r}154 \\
(81.6)\end{array}$ & $\begin{array}{r}166 \\
(83.8)\end{array}$ & $\begin{array}{r}102 \\
(83.6)\end{array}$ & $\begin{array}{r}147 \\
(94.2)\end{array}$ & $\begin{array}{r}91 \\
(94.8)\end{array}$ & $\begin{array}{r}1159 \\
(73.0)^{*}\end{array}$ & $1332(1208)$ \\
\hline Total & 127 & 212 & 264 & 201 & 201 & 208 & 122 & 156 & 96 & 1587 & \\
\hline
\end{tabular}

of the lesions $(1,005)$ presenting by the age of 6 years. Of the total of 1,587 lesions, $963(60.7 \%)$ had single surface cavities, 253 (15.9\%) had multiple surface cavities and 371 (23.4\%) were judged to have carious exposures of the pulp (Table 2). The most common lesion was found to be a single surface cavity in lower molar teeth, which comprised 342 (21.6\%) of the total number and 35.5\% of all single surface cavities. The same tooth type was also the most commonly exposed, giving $181(11.4 \%)$ of the total number and $48.8 \%$ of all exposed teeth. Figure 2 gives the percentage of cavity types by age of diagnosis.

Of the 1,587 teeth, 190 (12\%) were extracted because of pain and had a mean survival time from presentation to outcome of 766 days (outcome 1). A further 60 (3.8\%) became painful and were treated after a mean survival time of 649 days (outcome 2). Combining these two groups as teeth that gave pain produced a total of 250 (15.8\%), leaving $84.2 \%$, which remained symptomless until being lost. Of these symptomless teeth, 178 were extracted under general anaesthesia at the same time as painful ones, with a mean survival time of 650 days (outcome 3 ). This policy was often adopted to avoid the need for repeated general anaesthetics. The final group of 1,159 (73\%) teeth were exfoliated without causing pain after a mean survival time of 1,332 days (outcome 4). Exclusion from the analysis of outcome 3 teeth, on the basis that the true outcome of these teeth is unknown, leaves a total of 1,409 teeth of which $17.7 \%$ gave pain and were extracted or treated and the remaining 82.3\% exfoliated.

Three factors are associated with the outcome:

\section{Age at diagnosis}

This factor was found to be the strongest determinant of the development of pain. The percentage of carious teeth exfoliating without giving pain (outcome 4) increased with age of initial diagnosis from $47.2 \%$ of teeth diagnosed before the age of 3 years to $94.8 \%$ of those diagnosed after 9 years of age (Table 3 ). For the cavities presenting in children under 4 years of age $25 \%$ of carious teeth developed pain (outcome groups 1 and 2), compared with only 5\% of teeth presenting from 9 years of age (Fig. 3). For cavities presenting at age 4 or 5 years 19\% devel-

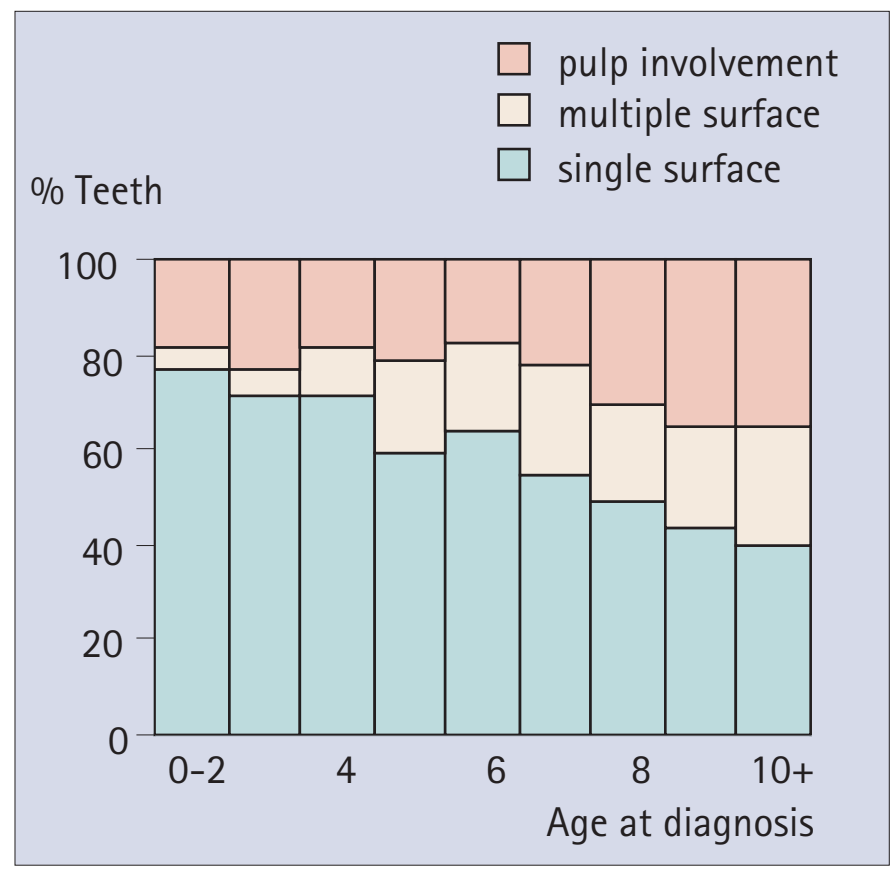

Fig. 2 The proportion of cavity types related to age at diagnosis 


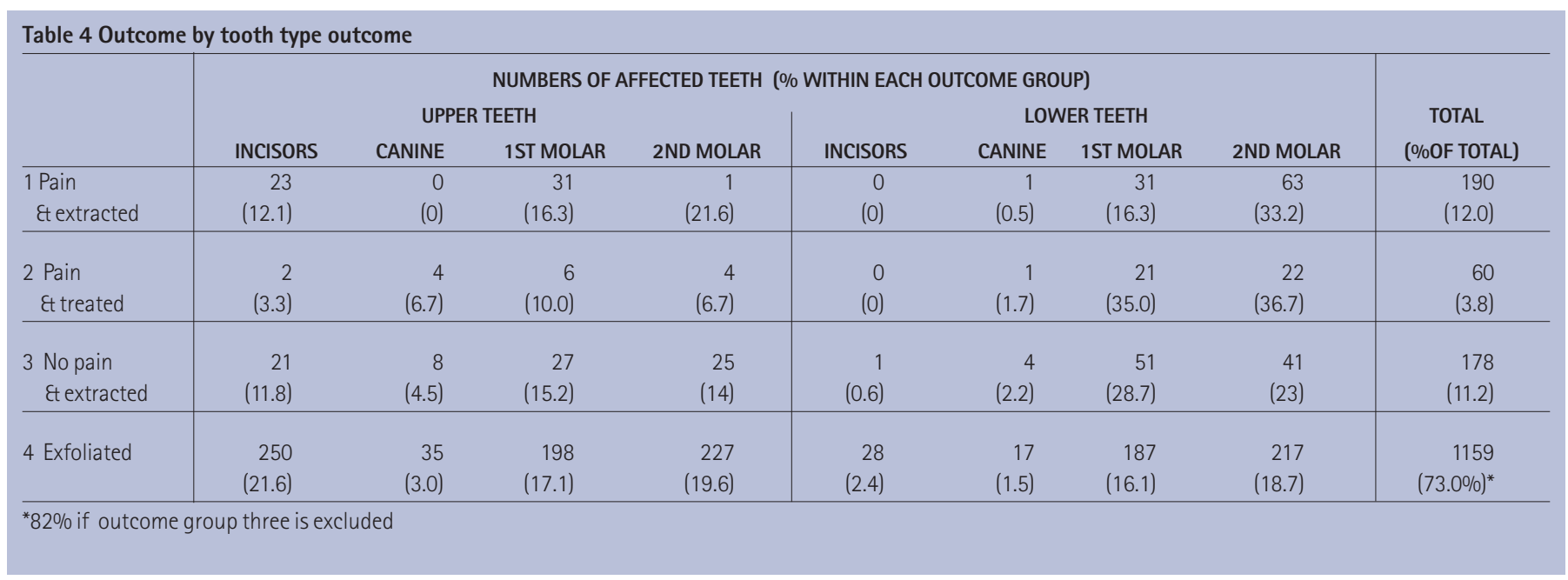

\begin{tabular}{|c|c|c|c|c|}
\hline OUTCOME & $\begin{array}{l}\text { NUMBERS OF AFFECTE } \\
\text { SINGLE SURFACE }\end{array}$ & $\begin{array}{l}\text { TEETH (\% WITHIN EAC } \\
\text { MULTIPLE SURFACES }\end{array}$ & $\begin{array}{l}\text { OUTCOME GROUP) } \\
\text { PULPAL EXPOSURE }\end{array}$ & $\begin{array}{c}\text { TOTAL } \\
\text { (\% OF TOTAL) }\end{array}$ \\
\hline 1 Pain \& extracted & $\begin{array}{r}95 \\
(50.0) \\
\end{array}$ & $\begin{array}{r}29 \\
(15.3)\end{array}$ & $\begin{array}{r}66 \\
(34.7) \\
\end{array}$ & $\begin{array}{r}190 \\
(12.0 \%)\end{array}$ \\
\hline 2 Pain \& treated & $\begin{array}{r}32 \\
(53.3)\end{array}$ & $\begin{array}{r}18 \\
(30.0)\end{array}$ & $\begin{array}{r}10 \\
(16.7)\end{array}$ & $\begin{array}{r}60 \\
(3.8 \%)\end{array}$ \\
\hline 3 No pain Et extracted & $\begin{array}{r}86 \\
(48.3) \\
\end{array}$ & $\begin{array}{r}22 \\
(12.4)\end{array}$ & $\begin{array}{r}70 \\
(39.3)\end{array}$ & $\begin{array}{r}178 \\
(11.2 \%)\end{array}$ \\
\hline 4 Exfoliated & $\begin{array}{r}753 \\
(65.0)\end{array}$ & $\begin{array}{r}183 \\
(15.8)\end{array}$ & $\begin{array}{r}223 \\
(19.2)\end{array}$ & $\begin{array}{c}1159 \\
(73.0 \%)^{*}\end{array}$ \\
\hline
\end{tabular}

oped pain, falling to $12 \%$ for cavities presenting from 6-8 years. Linear chi-square $\left(\chi^{2}\right)$ analysis of the relationship of age at diagnosis to pain produced a $P$ value of $<0.001$. It should be remembered that the age at diagnosis is not the same as age of onset of the lesion, which cannot be determined as many lesions were well advanced when first seen.

\section{Tooth type}

The results presented in Table 4 are for the combined age-at-diagnosis range and indicate that the lower anterior teeth are least likely to cause pain if carious, while the lower molars are most likely to do so. Comparing the age at diagnosis with tooth type showed that

Fig. 3 Outcome of pain (extracted or treated) related to age at diagnosis they differed significantly in their likelihood of becoming painful (outcome groups 1 and 2) for all age groups except children over 8 years $\left(\chi^{2} P<0.001\right)$. Of the teeth presenting with cavities in children under 4 years of age, pain occurred in 14\% of anterior teeth compared with $34 \%$ of posterior teeth. For cavities presenting at age 4 or 5 years, only $6 \%$ of incisors developed pain before being lost compared with $23 \%$ of canines and molars $\left(\chi^{2} P=0.002\right)$

\section{Cavity type}

Table 5 gives the outcome by cavity type with percentages within each outcome group, while Fig. 4 presents the proportions as a percentage of the total number of teeth. Cavity type was found to be a significant predictor of pain, with single surface cavities being less likely to cause pain than either multiple surface or exposed cavities (Linear $\chi^{2} P<0.05$ ), except in the oldest age group.

\section{Interaction of predictors}

Chi-squared interaction detection analysis was carried out using age at diagnosis, tooth type and extent of caries (single or multiple surfaces, pulpal involvement) as proposed predictors of pain. The first predictor was age (under 4, 4-5, 6-8, over $8 ; P<0.001$ ). Between these groups the next predictor varied.

\section{DISCUSSION}

This study has taken advantage of an unusual opportunity to study the outcome for carious lesions in deciduous teeth if left unrestored. However a discussion of the results of the analysis of the data must be preceded by consideration of compounding factors. Firstly it should be noted that the caries prevalence in Leeds and 


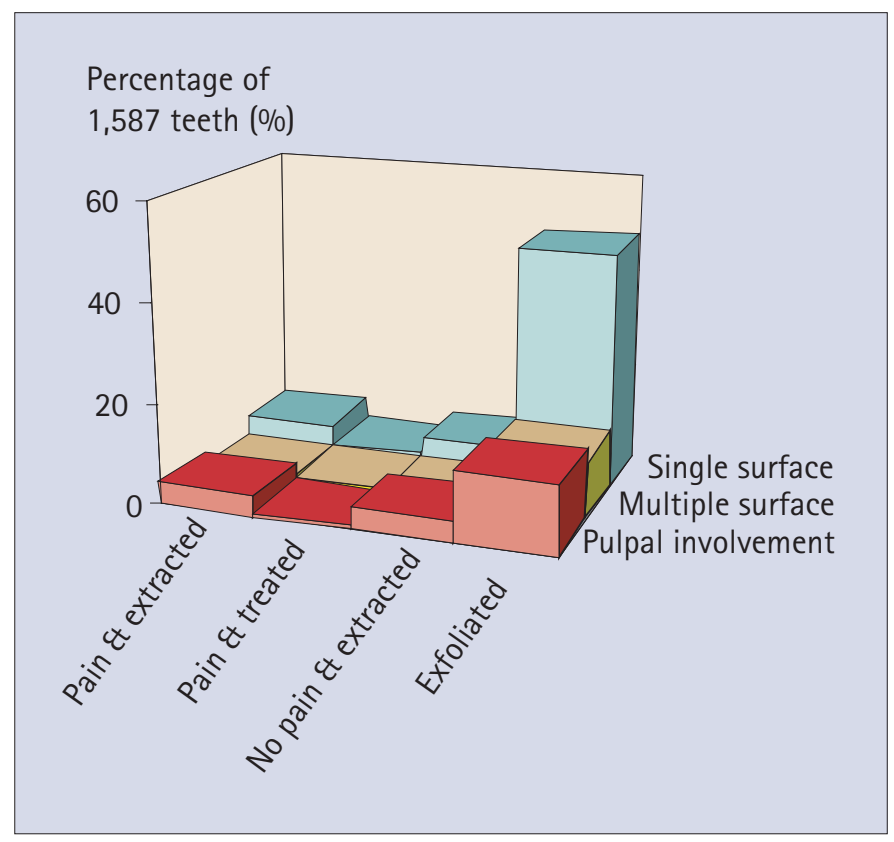

Fig. 4 Outcome related to cavity type

Halifax is higher than the national average. Of the children attending the Leeds practice, about 30\% were of Asian ethnic background. Evidence from studies on ethnicity and caries prevalence show high caries levels in the deciduous dentition but not in the permanent dentition. While the reason for this change is not fully understood, a change in dietary pattern has been implicated. Such a change may affect the progression of established carious lesions. While few children from ethnic minorities attended the Halifax practice, it is situated less than $1 \mathrm{~km}$ from a large biscuit factory employing many adults in the vicinity and $5 \mathrm{~km}$ from a large sugar confectionary factory.

The second factor is the clinical management provided for the subjects of this study. It must be emphasised that non-restoration is not the same as lack of management. All children with caries experience were provided with appropriate dietary advice to reduce the frequency of sugars intake, reinforced at each recall visit, together with advice on twice daily brushing with fluoride toothpaste, supervised by parents until at least the age of 7 years. Dietary analysis over 3 days followed by counselling and toothbrushing instruction for children and patients were often provided. Where appropriate, fluoride dietary supplements were prescribed. Such intensive preventive care may have had an effect on the progression of carious lesions.

There is little in the published literature with which to compare the present findings. In a retrospective case note review of 430 5 -year-old children in north west England it was found that only $29 \%$ of carious teeth in children regularly attending seven general dental practices had been treated by conventional restoration. ${ }^{6}$ While the reason for this pattern of care was not investigated, it may be assumed that it was based on a pragmatic approach to whole patient care. The study concluded that a consensus is needed across the profession on the care of the diseased deciduous dentition. A report in abstract form of a retrospective study of the case notes of 677 children receiving regular dental care from 50 general dental practitioners in northern England compared the outcome of restored and unrestored carious deciduous teeth. ${ }^{7}$ Using the development of pain or sepsis as an outcome, no difference was found between restored teeth and those left unrestored. A Finish study on the dental care of 3-7-year-old children with high caries experience found that 34\% were judged to be non-cooperative and of these only 39\% completed their treatment compared with 63\% of cooperative patients. ${ }^{8}$

The results of the present study provide a picture of unrestored caries outcome that will surprise few experienced clinicians. The carious teeth most likely to go on to cause pain are those with larger cavities in molar teeth presenting shortly after eruption. The earlier a tooth decays prior to natural shedding, the longer it is in the mouth and the greater the likelihood of pain. In contrast, cavities, which only develop nearer the time of natural shedding, are unlikely to cause pain. Overall, only $16 \%$ of carious deciduous teeth left unrestored went on to cause pain requiring treatment or extraction with a mean survival time of 740 days. The remaining $84 \%$ of teeth studied remained painfree until being naturally shed after a mean interval of 1,241 days from diagnosis.

These findings should be interpreted with a degree of caution because of the compounding factors, which have been discussed. They should not be taken as an indication that all carious deciduous teeth be left unrestored; sound clinical judgement will indicate cases where restoration is appropriate. The outcome criteria used in this study focused on pain and it should be noted that carious deciduous teeth can produce painless alveolar infection with the potential for serious dental and systemic consequences. The protocol used in these practices allowed for appropriate care of medically compromised children.

The authors, who are not specialist paedodontists, wish to emphasise that they are not advocating the adoption of a general policy of not restoring carious deciduous teeth and the findings presented here should not be taken as such. However this study provides evidence that may stimulate discussion and may be an aid to clinicians in making the best management decisions. Considerations for such decisions may include those factors that have been investigated together with an assessment of the child's medical and dental history, family and social factors, the child's temperament and confidence. Factors which may retard the progress of lesions, such as fluoride content of the water supply and use of topical fluorides, may be relevant. A further consideration for treatment planning in the UK is the cessation of general anaesthesia in general dental practice from 2002. Above all, it is suggested that the benefit to the child from operative intervention, in terms of freedom from pain and the development of a healthy permanent dentition, should be critically assessed against the background of the present findings.

The authors are grateful to Mrs Carol-ann Levine and Mrs Kathryn Hopkins for their assistance. This study was supported by a grant from the Shirley Glasstone Hughes Memorial Fund, which is gratefully acknowledged.

1. Pitts N B, Evans D J, Nugent Z J. The dental caries experience of 5-year-old children in Great Britain. Surveys coordinated by the British Association for the study of Community Dentistry in 1999/2000. Community Dent Health 2001; 18: 49-55.

2. Curzon M E J, Pollard M A. Do we still care about children's teeth? Br Dent J 1997; 182: $242-244$

3. Levine R S. Towards the chemotherapeutic treatment of dental caries: a review. JRoyal Soc Med 1980; 73: 876-881.

4. Pitts N B. Do we understand which children need and get appropriate dental care? BrDent J 1997; 182: 273-178.

5. Levine R S (Ed.). The scientific basis of dental health education, 4th ed. London: The Health Education Authority, 1996.

6. Tickle M, Williams M, Jenner T, Blinkhorn A. The effects of socioeconomic status and dental attendance on dental caries experience and treatment patterns in 5-year-old children. BrDent J 1999: 186: 135-137.

7. King D, Milsom K M, Tickle M, Blinkhorn A S. Is it a good idea to fill deciduous teeth? Community Dent Health 2000; 17: 199

8. Varsio S, Vehkalahti M, Murtomaa B. Dental care of six-year-old high-caries patients in relation to their cooperation. Community Dent Health 1999; 16: 171-175. 